\title{
Using Jungian Personality Types for Teaching Teamwork in a Software Engineering Capstone Course
}

Citation for published version (APA):

Pieterse, V., Stuurman, S., \& van Eekelen, M. C. J. D. (2021). Using Jungian Personality Types for Teaching Teamwork in a Software Engineering Capstone Course. In Proceedings of the 52nd ACM Technical Symposium on Computer Science Education (pp. 239-245). acm. https://doi.org/10.1145/3408877.3432455

DOI:

$10.1145 / 3408877.3432455$

Document status and date:

Published: 03/03/2021

\section{Document license:}

Taverne

Please check the document version of this publication:

- A submitted manuscript is the version of the article upon submission and before peer-review. There can be important differences between the submitted version and the official published version of record. People interested in the research are advised to contact the author for the final version of the publication, or visit the DOI to the publisher's website.

- The final author version and the galley proof are versions of the publication after peer review.

- The final published version features the final layout of the paper including the volume, issue and page numbers.

Link to publication

\section{General rights}

Copyright and moral rights for the publications made accessible in the public portal are retained by the authors and/or other copyright owners and it is a condition of accessing publications that users recognise and abide by the legal requirements associated with these rights.

- Users may download and print one copy of any publication from the public portal for the purpose of private study or research.

- You may not further distribute the material or use it for any profit-making activity or commercial gain

- You may freely distribute the URL identifying the publication in the public portal.

If the publication is distributed under the terms of Article 25fa of the Dutch Copyright Act, indicated by the "Taverne" license above, please follow below link for the End User Agreement:

https://www.ou.nl/taverne-agreement

Take down policy

If you believe that this document breaches copyright please contact us at:

pure-support@ou.nl

providing details and we will investigate your claim.

Downloaded from https://research.ou.nl/ on date: 26 Apr. 2023 


\section{Using Jungian Personality Types for Teaching Teamwork in a Software Engineering Capstone Course}

\author{
Aaa \\ AA \\ Aaa@AA
}

\author{
$\mathrm{Bbb}$ \\ $\mathrm{BB}$ \\ Bbb@BB
}

\author{
Ccc \\ $\mathrm{CC}$ \\ Ccc@CC
}

\begin{abstract}
We apply the Jungian personality types to augment the teaching of teamwork skills to Software Engineering (SE) students on third year university level in our capstone course. We describe how we introduce knowledge of the Jungian personality dimensions to our students. We propose an innovative method to gather information about the personality preferences of our students. The method deviates from the usual as it does not use a personality inventory survey. Instead it relies on observations made by peers.

We give an account of the activities we implemented to instil understanding of the personality concepts associated with the Jungian personality types. Data was gathered during these activities. We analyze the data to get an impression of the distribution of Jungian personality dimensions in our student population. We discuss the implications of our observations and conclude that the practicality of knowledge of the Jungian personality types is beneficial in our context.

We discuss how the students' participation in the activities to gather information about their own and their teammates' personalities helped them to apply the concepts associated with the Jungian Personality types to improve their interpersonal skills and teamwork skills.
\end{abstract}

\section{CCS CONCEPTS}

- Software and its engineering $\rightarrow$ Programming teams.

\section{KEYWORDS}

Personality types, Jungian personality types, Team skills, Professional skills

\section{ACM Reference Format:}

Aaa, Bbb, and Ccc. 2019. Using Jungian Personality Types for Teaching Teamwork in a Software Engineering Capstone Course. In Proceedings CSERC 2019 19-20 October 2020 Computer Science Education Research Conference, Online (CSERC '20), October 19-20, 2020, Online. ACM, New York, NY, USA, 7 pages. https://doi.org/xx

\section{INTRODUCTION}

The ability to work effectively in a team is an essential skill for computer science graduates $[10,31,35]$. Facilitating a team-building

Permission to make digital or hard copies of all or part of this work for personal or classroom use is granted without fee provided that copies are not made or distributed for profit or commercial advantage and that copies bear this notice and the full citation on the first page. Copyrights for components of this work owned by others than ACM must be honored. Abstracting with credit is permitted. To copy otherwise, or republish, to post on servers or to redistribute to lists, requires prior specific permission and/or a fee. Request permissions from permissions@acm.org.

CSERC '20, October 19-20, 2020, Online

(C) 2019 Association for Computing Machinery.

ACM ISBN xx...\$15.00

https://doi.org/xx educational experience to introduce the benefits and skills needed for successful teams can be challenging [7]. Researchers agree that the personality of team members and the composition of teams in terms of the personalities of the members may influence the cohesion and effectiveness of software engineering teams [20, 29, 30, 33].

The Jungian Personality types are often the vehicle used in industry to assist in various types of counselling. We are aware that this personality theory and its use have been criticised [28]. Despite the criticism, personality measures remains widely used to help people to better understand themselves and others. In most cases validated surveys are used to determine Jungian personality types, for example the well known Myers-Briggs Type Indicator (MBTI) [26], Keirsey Temperament Sorter (KTS) [18], The Personal Preferences Self-Description Questoinnaire (PPSDQ) [36, 37] and Gray-Wheelwrights Jungian Type Survey (GW/JTS) [6, 41].

An example of constructive use of the Jungian personality types to assist students to develop their personalities can be seen in Varvel et al.'s [2004] instruction of senior engineering design students about the Jungian dimensions. They purport that the training helped the students to be more effective in their teams through improvement of teamwork skills such as communication, trust, and interdependence.

Knowledge about the Jungian personality dimensions contributes to a better understanding of other people and of oneself. This can aid the development of interpersonal and leadership skills and it can also help a person to make better decisions about his/her own personal development. The way in which we apply the theory deviate from the norm as we do not attempt to identify the personality type of individuals or aspire to give advice to individuals based on their personality type. We merely discuss the personality differences as identified in terms of the Jungian types and provide general guidelines which the students can apply to improve mutual understanding. Even though some of the claims that are based on this theory can not be scientifically asserted, we deem the anecdotal truth and practicality of the theory useful in our education.

The availability and costs associated with using validated surveys for determining the Jungian personality types of our students prevented us from using any of those that we are aware of, or questionnaires which could be found online, such as the survey by Boeree [1]. Instead our students were sensitised to their own and their peers' Jungian personality type by means of informal surveys.

Section 2 gives an overview of the Jungian types, its history and its application. Section 3 provide information about personality assessment which informed our method of personality assessment. Our method is an integral part of how we use the Jungian types as part of the Software Engineering curriculum. The method is justified based on research findings reported in literature related to 
personality assessment. We contend that our method to obtain personality ratings is easy to administer and is suitable for our purpose. Section 4 describes how we incorporate the personality theory in our teaching mostly as a means to assist students to develop interpersonal skills and teamwork skills. These soft skills are deemed important in a well-rounded software engineering course to advance the employability of the students. Finally, Section 5 discusses how our students experienced the application of our method and the activities surrounding the method. We believe that our method of using the Jungian personality types to introduce personality differences to our students is easy and requires a minimal amount of notional time to administer. It provides useful information and helps student teams to handle internal oppositions in a constructive manner.

\section{JUNGIAN PERSONALITY THEORY}

\subsection{Historical overview}

Carl Jung (1887 - 1961) was a Swiss physician-psychologists. His personality theory was inspired by a process of self-exploration that was triggered by lucid dreams and visions [1]. He defined extraversion and introversion as the two fundamental attitudes that people adopt to make sense out of their experience [32]. Alongside with these fundamental attitudes, Jung postulated four ways (called functions) in which people relate to the world: sensing, thinking, feeling and intuiting. These four functions were used by personality scholars building on Jung's theories for the definition of the two dimensions Sensing-Intuiting and Thinking-Feeling [1]. Briggs and Briggs-Myers added an extra dimension, namely Judging-Perceiving, which was implicit in Jung's theory. [9].

\subsection{Jungian Personality Preferences}

The premises of the Jungian personality theory is that people differ in terms of four identified dimensions. In each of the dimensions, a person is likely to prefer to act according to one of the poles of the dimension above the other pole. Capretz [3], however, emphasises that everyone uses all eight preferences, not merely the four which are preferred. It is further assumed that the behaviour of people relates to their current situation and is constantly influenced by their environment [24, 25].

The following is a summary of the personal qualities of people according to the Jungian dimensions compiled by combining descriptions that can be found in Gorla and Lam [12], Kuipers et al. [19], Pieterse et al. [30], Stein and Swan [34], the website of the Myers-Briggs Foundation ${ }^{1}$ and many other publications:

2.2.1 Social interaction (I-E). This dimension distinguishes between Introverts and Extroverts. Introverts usually think things through before acting. They are comfortable with long silences and prefer to work alone. Extroverts tend to talk about anything just to break the silence and enjoy interacting with others. Sometimes they may act before thinking. Meetings tend to drain introverts while extroverts are energized by social interaction. Extroverts take an interest in broad topics while Introverts would rather concentrate on a few, deep issues.

$\overline{{ }^{1} \text { https://www.myersbriggs.org/my-mbti-personality-type/mbti-basics/ }}$
2.2.2 Gathering information $(S-N)$. According to this dimension a person is considered to be either Sensing or iNtuitive when observing information. A sensing person prefers tangible results, pays attention to detail and values information based on concrete, clear and detailed information. An intuitive person has a more holistic view, sees facts as contributors to concepts and tends to be more imaginative and interested in what is not yet known. Sensors take a practical approach while intuition looks at potential and possibilities.

2.2.3 Making decisions (T-F). According to this dimension some people can be described as Thinkers and others as Feelers when they have to decide. Thinking people are objective, orderly and critical. They base their decisions on principles and logic. Feeling people are driven by personal values and bases judgments on subjective and personal considerations. Thinkers focus on tasks and may act like detached onlookers. They consider people and would take a personal, subjective view as a participant.

2.2.4 Work style (J-P). Work style is defined to be Judging or Perceiving. Judgers are organised individuals. They plan ahead and prefer closure to avoid last minute stresses. They are inclined to establish deadlines and expect others to follow. They like to be in control and prefer closure and stability. Perceivers are flexible and inquiring people. They prefer to be spontaneous and to leave things open in anticipation of a better opportunity that might arise. They are energized by pressure.

\subsection{Application}

Understanding of the Jungian personality types and how people differ in how they prefer to energise, gather information, make decisions and organise their lives, helps a person to make sense of their own behaviour and the behaviour of other individuals. Such apprehension of possible reasons for the actions of others is likely to strengthen interpersonal relationships and may enhance an individual's teamwork skills [19, 25, 38].

a synopsis of the application of Jungian dimensions to improve synergy in teams can be found at https://www.metarasa.com/relationships/. We use these guidelines in our application described in Section 4.

\section{PERSONALITY ASSESSMENT}

In professional psychology, personality assessment involves the administration, scoring, and interpretation of empirically supported measures of personality traits and styles with the aim to diagnose or predict behaviour. In contrast, our personality assessment is merely used as a vehicle to sensitise the students to the acknowledgement of personal differences and to serve as a framework for guidelines to deal with different personalities in their teams.

Our method of personality assessment is unique in terms of the following aspects:

- Where it is common to use only self-rating or peer observations, we combine self-reporting with peer observations. This is done to minimise bias which can be caused by either self-rating or observations by others.

- Our method uses a single direct rating item to evaluate each personality dimension, whereas the use of multiple items is the norm. This is done to avoid respondent fatigue and 
to reduce notional time spent. In Section 3.1 we justify the validity of this minimalist approach.

- Our method of gathering data related to the personality of our students, is integrated with general reflection required from our students. Instead of asking only personality related questions, the personality questions are part of broader surveys aimed at stimulating reflection on all learning experiences.

- Our method has the unique feature that it is conducted over multiple surveys at different times, each time focusing on only one personality dimension, whereas dedicated personality surveys are usually conducted in one go covering the whole personality spectrum.

We discuss our method and the benefits of gathering the data over multiple sessions and combining personality assessment with general assessment in more detail in Section 3.2.

\subsection{Methods of assessment}

There are many methods to establish personality attributes of people. For example by observing how they behave, what they wear, the activities in which they participate, what they say, how they talk, what they write, what they read, etc. Behavioural measures are considered beneficial as traits are overtly expressed through behaviour [23].

Despite the variety of behavioural observations which could be applied, the use of questionnaires to ascertain personal attributes of people dominates the personality measurement scene. For example, [17] states that more than $95 \%$ of studies reported in the Journal of Personality in 2006 used self-report questionnaires.

When direct rating scales are used, instead of multiple items which are designed to measure a trait, the number of items in a questionnaire can be reduced without significant impact on the validity of the measurements. For example, Gosling et al. [13] created a five-item personality inventory (FIPI) consisting of a single item per factor of the widely used Five-Factor personality model [16, 22]. The FIPI instrument can stand as a reasonable proxy for a number of accepted longer Big-Five instruments [13].

Burisch [2] cites numerous studies that have found that if you ask subjects to rate themselves directly on simple trait-rating scales, these self-ratings turn out, on average, to be more valid than corresponding questionnaire scales.

\subsection{Our method}

We conduct questionnaires to assess the personality of our students. Where most personality questionnaires would use multiple items to measure a trait, we opt to use only one direct rating scale for each of the dimensions of the Jungian personality construct. This technique has been found to be a sound proxy [13]. Having fewer questions is likely to increase the response rate and the quality of the responses [11]. It, furthermore, minimises undue notional time spent on the aspect of personality in a curriculum which spans a broad spectrum of SE concepts, techniques and strategies.

We do not include all the items in one questionnaire. Instead, we assess only one personality dimension at a time. This strategy simplifies observation and self-reflection since students compare and contrast the behaviour of the members of their team only in terms of a single personality dichotomy. This focused attention may contribute to the accuracy of the data gathered in this manner.

We combine self-reporting with peer-reporting to reduce bias and increase accuracy. Students are required to rate their own preferences as well as the preferences of their peers as described in Section 4.2. The responses are used to calculate a preference scale and identify the dominant preference for each student for each of the Jungian dimensions as described in Section 4.3.

We allow for the inclusion of observational information. Although our method involves only answering a single rating question in a questionnaire, we assume that the information provided by the respondents about their peers is mostly based on behavioural observations they have made prior to answering the survey.

The questionnaires we use as a vehicle to obtain information about the personality of our students are holistic i.e. each questionnaire contains questions related to team activities which are commonly not related personality issues. This way the students are stimulated to think about the personality dimensions in the context of their team activities emphasising the practicality of each personality concept.

\section{EXPLORING PERSONAL DIFFERENCES}

\subsection{Sensitising students to the concepts}

At the beginning of each of four different lectures in the course of the module, the students are informed about an upcoming reflection review (Section 4.2). In each case, about ten minutes of a fifty minute lecture (covering other material included in our curriculum), is devoted to explaining the characteristics exemplifying the poles of one of the Jungian personality dimensions as discussed in Section 2.2.

We are particularly cautious to avoid creating the impression that one of the poles of a particular dimension may be socially more desirable or more beneficial to the team than the other. We reinforce this concept by elaborating the positive consequences of leaning towards each of the poles of a given dimension. We also discuss the unique contributions of such an individual to the success of the team. For example, when discussing the T-F dimension we point out that a thinker has the propensity to analyze information objectively and make a reasoned judgment. Analytic thinking is a core skill to perform many aspects of software engineering, such as systems analysis, design, programming, and testing [15]. On the other hand, a feeler can contribute to the team's emotional awareness i.e. paying attention to noticing, understanding, and respecting the feelings of team members. Emotional awareness is a critical factor in motivation, productivity, and a team's ability to collaborate $[5,14]$.

We further emphasize that having a clear preference (gravitating to a certain pole) is not better or worse than not exhibiting a clear preference (hovering between the poles).

In conclusion of the ten minute discussion of the particular Jungian personality dimension, we summarize the clues contrasting the poles of the dimension.

\subsection{Reflection to reinforce understanding}

Shortly after being lectured on one of the dimensions of the MBTI typology as described in Section 4.1, students are expected to think 
about their own preference considering the particular dimension and also to propose their opinion of the preferences of the other members of their team, based on clues typifying the extremes of the dimension that was given during the lecture. They do this by rating each member in their team using a six-point Likert scale ranging from the one pole of the personality dimension to the other. The six-point scale forces the students to decide on a dominant preference for each member since there is no neutral option. They are, however, permitted to choose not to answer the question.

This reflection on the personality preferences of the members of their teams forms part of a more comprehensive peer review questionnaire the students are expected to complete at regular intervals. These reviews afford the students opportunities to evaluate the effectiveness of their team and its members [4, 8]. It is believed that the use of peer reviews improves learning and contributes to uniform assessment [40]. The questions are intended to guide them to reflect on their own contributions in relation to those of the other members in their team [21].

The inclusion of the question to reflect on the personality preferences of the members of the team contributes to improvement of interpersonal relations in the team. It is intended to reinforce the students' understanding of how people may differ in their motivation and behaviour. This understanding is further contextualised to their own teams through further discussion as described in Section 4.3.

\subsection{Team discussions}

After completion of the peer review, the instructor analyses the responses of the students on a per team basis. Responses to all questions in the review are analysed. Here, we discuss only the analysis and use of the responses to the question regarding the personal preferences of the members. It is used to get an impression of the distribution of the preferences of the members of the team regarding the single Jungian personality dimension under consideration.

For each member, the average of the Likert scale values, for the dimension under consideration, nominated by the members of the team, is calculated. Based on the SOKA model Vazire [39], the value of the self-reported preference is counted twice for the dimensions low in observability, namely the T-F and J-P dimensions. When the total is zero, it means that equal counts of the opposite poles are nominated. In this case, the preference for the dimension is taken as neutral. We use the result to visualise each team profile. Figure 1 shows a sample of such a team profile. M1 ... M5 represent the names of the team members. In this sample, the members are sorted from most extroverted to most introverted.

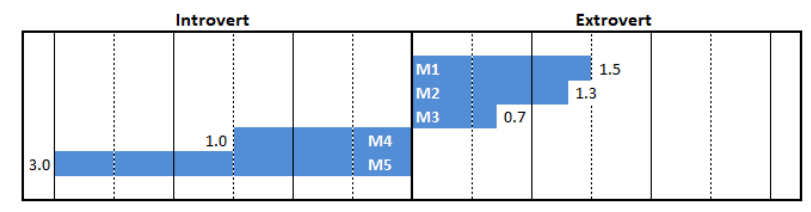

Figure 1: Example Introversion-Extroversion team profile

The results and interpretation of the analysis are then discussed with each team at a scheduled team meeting. We highlight the strengths of each member and the unique personal contributions he/she brings to the team, especially for those individuals who are clearly leaning towards a certain pole. We are cautious to keep the feedback and discussion positive by nature and aimed at nurturing acceptance in the team. In this particular case we emphasise that having an extreme introvert, in the person of M5, has the benefit of the natural inclination of this person to work long hours solo to solve a difficult problem. The team should trust his/her discretion as he/she is likely to think things through before making decisions. These guidelines will boost the confidence of M5 and also provide subtle guidelines for the rests of the team to make an effort to hear M5's opinion as he/she is unlikely to offer it voluntarily.

Where a certain preference is dominant in the team (for example a team of mostly introverts and only one mildly extroverted member), we point out that the situation is beneficial for mutual understanding as most members have similar behaviour. We also advise the team members of such a team to make an effort to sometimes force themselves to behave according to the opposite pole. This should be done to compensate for the fact that the scarcity of the natural inclination to that behaviour may have a negative effect on the achievement of the team.

It is interesting to observe that many of our students have ratings closer to being undecided on a personality preference and that only a few students have been rated to portray any of the preferences to the extreme. This confirms that most of our students use all eight preferences when working in their teams and have the ability to behave in ways that are beneficial to their teams.

\section{IMPACT OF THE ACTIVITY}

We include two open-ended questions in each peer review questionnaire. The questions are:

(1) What have you learned the past two weeks?

(2) Write anything you would like to say to the lecturers.

We deliberately formulate the questions in this non-specific way to avoid demand responses i.e. the tendency of respondents to answer in a way they think the researcher expects [27]. Besides creating an opportunity for students to communicate openly with their lectures, it also provides a rich source of information regarding the successes and failures of our teaching.

In our analysis of student responses to the first of these two questions between 2012 and 2014 we established that $26.7 \%$ of responses refer to technical skills they have learned and $86.7 \%$ discuss social skills. The second question is often left unanswered. When answered, it often includes praise to the lecturers but also frequently points to dissatisfaction with how we teach.

In this article, we analysed 691 responses to these questions which were given by students in the period from 2014 to 2016 . Of the 691 responses, only $162(23.4 \%)$ were related to the application of the Jungian personality dimensions. We further analysed these 162 responses with the aim to determine how our students experienced learning about personalities and applying the guidelines we offered in this regard. The following themes emerged:

\subsection{Resistance}

Some students resented the idea of having to deliberate personality dimensions or having to form an opinion about the personality of 
others. The quotes in figure 2 are examples of comments related to this theme.

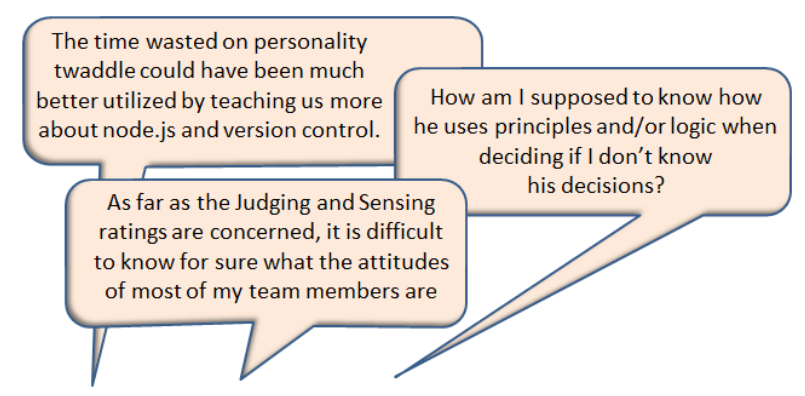

Figure 2: Comments by students who were uncomfortable with the activity

\subsection{Conscious effort}

Students apprehend that it may require conscious effort to fruitfully apply the ideas posed to them during the activity. Although in theory it seems simple, some students may find it difficult to implement the guidelines we gave them. See Figure 3 for comments by students who acknowledge that they have to exert effort to accomplish the goals of the activity.

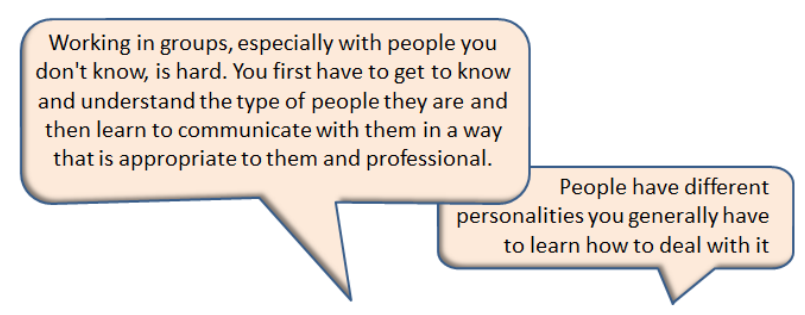

Figure 3: Comments by students who refer to effort required to apply the given guidelines

\subsection{Fascination}

Many students find the facts regarding the personality types interesting or informative. They came to a realisation of personal differences but do not necessary know how such knowledge can be applied in the context of Software Engineering teamwork. The quotes in figure 4 are examples of comments by such students.

\subsection{Practicality}

Students have realised that knowledge about the strengths and weakness associated with certain personality attributes may be useful. They see the benefit of taking personal preferences into account when dividing their work in order to make the most of the personal strengths of the members of the team. Figure 5 show some remarks by students confirming this.

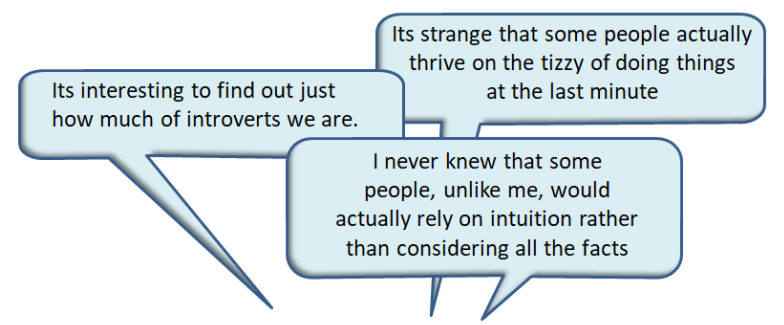

Figure 4: Comments by students who are appealed by concepts of personal differences

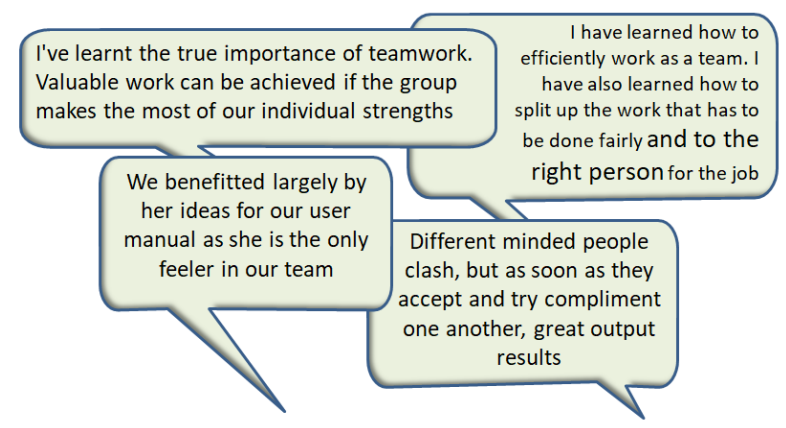

Figure 5: Comments by students who appreciate the use of personal differences

\subsection{Improved cooperation}

Deeper knowledge about the personal differences of the members of a team can contribute to improving interpersonal relations and enhancing mutual trust between the members of the team. Figure 6 shows some remarks by students who accredit their newly gained knowledge about personality eccentricities for improved cooperation in their teams.

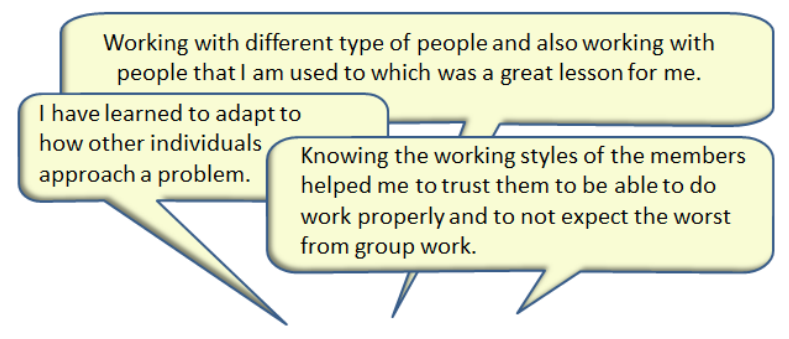

Figure 6: Comments by students who appreciate the use of personal differences

\subsection{Soft skills development}

Leadership skills and interpersonal relations can be improved through introspection and knowledge about suitable treatment of certain personality types. See Figure 7 for comments by students affirming that the guidance given during the activity has contributed to the development of their soft skills. 


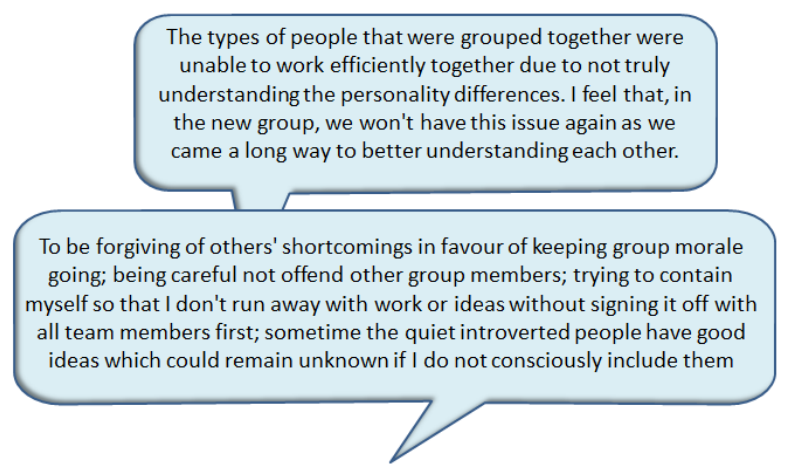

Figure 7: Comments by students who attest to soft skills development

\subsection{Personal growth}

There were students who observed how they can apply the knowledge and understanding regarding their own preferences towards self-improvement. The comments shown in Figure 8 are testimonies of students telling how it has assisted their personal growth.

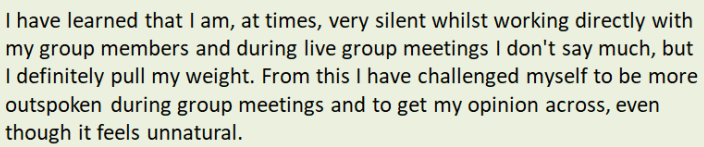

Figure 8: Comments by students who attest to their personal growth

\section{CONCLUSION}

We advocate that the Jungian personality theory is a practical means to highlight the strengths and potential weaknesses of team members which in turn can improve inter-personal relations and enhance mutual trust within teams.

We justify and explain a novel and easy method we applied to determine information regarding the Jungian personality preferences of our students. The information has proven to be a useful instrument to administer fruitful team discussions.

We describe how we use the Jungian personality theory in our curriculum. We find the use of the information effective. We contend that the possible limitations of our method, does not detract from the practical usefulness of the information in our context. Regular team discussions are beneficial anyhow, and having a vehicle such as the personality preferences of the members to structure the discussion adds value to such discussions. In our context, the information is used at face value and without asserting scientific claims when guiding teams to appreciate and capitalise on the strengths of their members in order to improve cooperation and the overall performance of the team.

We investigated the impact of our teaching activities involving the application of Jungian personality theory on our students. Not all students are equally appreciative of the practicality of our approach and the benefits of including it in the curriculum. Nonetheless, we have observed that many individual students have exerted conscious effort to apply their understanding of the Jungian preferences for personal growth and for the development of their leadership skills. Most of our students have testified of its positive impact on their learning and success.

\section{REFERENCES}

[1] C. George Boeree. 2006. Personality Theories: Carl Jung. https://webspace.ship.edu/cgboer/jung.html. Accessed: July 21, 2019.

[2] Matthias Burisch. 1984. Approaches to personality inventory construction: a comparison of merits. American Psychologist 39, 3 (1984), $214-227$.

[3] Luiz Fernando Capretz. 2003. Personality types in software engineering. International fournal of Human-Computer Studies 58, 2 (2003), 207-214.

[4] Jianguo Chen, Huijuan Lu, Lixin An, and Yongxia Zhou. 2009. Exploring teaching methods in software engineering education. In 2009 4th International Conference on Computer Science Education. Institute of Electrical and Electronics Engineers ( IEEE ), Piscataway, New Jersey, USA, 1733 - 1738. https://doi.org/10.1109/ICCSE. 2009.5228269

[5] John D Cox. 2011. Emotional intelligence and its role in collaboration. In Proceedings of The American Society of Business and Behavioral Sciences (ASBBS), Vol. 18 (1). American Society of Business and Behavioral Sciences, San Diego, USA, 435-445.

[6] Melinda F. Davis and Mary Ann Mattoon. 2006. Reliability and Validity of the Gray-Wheelwrights Jungian Type Survey. European fournal of Psychological Assessment 22, 4 (2006), 233-239.

[7] Marguerite Doman, Andrew Besmer, and Anne Olsen. 2015. Managing Software Engineering Student Teams Using Pellerin's 4-D System. Fournal of Information Systems Education 26, 4 (2015), 257-264. https://aisel.aisnet.org/jise/vol26/iss4/1

[8] Robert Drake, Geraldine Goldsmith, and Rebecca Strachan. 2006. A novel approach to teaching teamwork. Teaching in Higher Education 11, 1 (2006), 33-46. https://doi.org/10.1080/13562510500400115 arXiv:http://dx.doi.org/10.1080/13562510500400115

[9] John A Edwards, Kevin Lanning, and Karen Hooker. 2002. The MBTI and Social Information Processing: An Incremental Validity Study. Fournal of Personality Assessment 78, 3 (2002), 432-450.

[10] Sunet. Eybers and Marié J. Hattingh. 2019. The Last Straw: Teaching Project Team Dynamics to Third-Year Students. In ICT Education: 48th Annual Conference of the Southern African Computer Lecturers' Association, SACLA 2019, Northern Drakensberg, South Africa, Fuly 15-17, 2019. Communications in Computer and Information Science, S Kabanda, Suleman H., and Gruner S. (Eds.), Vol. 963. Springer International Publishing, Cham, 237-252.

[11] Mirta Galesic and Michael Bosnjak. 2009. Effects of Questionnaire Length on Participation and Indicators of Response Quality in a Web Survey. Public Opinion Quarterly 73, 2 (05 2009), 349-360. https://doi.org/10.1093/poq/nfp031

[12] Narasimhaiah Gorla and Yan Wah Lam. 2004. Who Should Work with Whom?: Building Effective Software Project Teams. Commun. ACM 47, 6 (June 2004), 79-82. https://doi.org/10.1145/990680.990684

[13] Samuel D Gosling, Peter J Rentfrow, and William B Swann. 2003. A very brief measure of the Big-Five personality domains. Fournal of Research in Personality 37, 6 (2003), $504-528$.

[14] Emitza Guzman and Bernd Bruegge. 2013. Towards Emotional Awareness in Software Development Teams. In Proceedings of the 2013 9th foint Meeting on Foundations of Software Engineering (ESEC/FSE 2013). ACM, New York, NY, USA, 671-674. https://doi.org/10.1145/2491411.2494578

[15] Chenglie Hu. 2011. Computational Thinking: What It Might Mean and What We Might Do About It. In Proceedings of the 16th Annual foint Conference on Innovation and Technology in Computer Science Education (ITiCSE '11). ACM, New York, NY, USA, 223-227. https://doi.org/10.1145/1999747.1999811

[16] Oliver P John and Sanjay Srivastava. 1999. The Big Five trait taxonomy: History, measurement, and theoretical perspectives. Handbook of personality: Theory and research 2, 1999 (1999), 102-138.

[17] Jerome S. Kagan. 2007. A Trio of Concerns. Perspectives on psychological science : a journal of the Association for Psychological Science 2, 4 (2007), 361-376.

[18] David Keirsey and Marilyn M Bates. 1984. Please understand me. Prometheas Nemesis. 
[19] Ben S. Kuipers, Malcolm J. Higgs, Natalia V. Tolkacheva, and Marco C. de Witte. 2009. The Influence of Myers-Briggs Type Indicator Profiles on Team Development Processes: An Empirical Study in the Manufacturing Industry. Small Group Research 40, 4 (2009), 436-464.

[20] Vanja Ćatić Kuko, Denis Mušić, Zanin Vejzović, and Jasmin Azemović. 2019. Model of foresight work habits of agile software team members by personality traits. In 2019 International Conference on Computer, Information and Telecommunication Systems (CITS). 1-5. https://doi.org/10.1109/CITS.2019.8862095

[21] Linda Marshall, Vreda Pieterse, Lisa Thompson, and Dina M. Venter. 2016. Exploration of Participation in Student Software Engineering Teams. ACM Transactions on Computing Education (TOCE) 16, 2, Article 5 (Feb. 2016), 38 pages. https://doi.org/10.1145/2791396

[22] Robert R McCrae and Paul T Costa. 1987. Validation of the five-factor model of personality across instruments and observers. fournal of personality and social psychology 52, 1 (1987), $81-90$.

[23] Jennifer Dodorico McDonald. 2008. Measuring personality constructs: The advantages and disadvantages of self-reports, informant reports and behavioural assessments. Enquire 1, 1 (2008), 75 - 94.

[24] Walter Mischel. 2004. Toward an Integrative Science of the Person. Annual Review of Psychology 55, 1 (2004), 1-22.

[25] Penny Moyle and John Hackston. 2018. Personality Assessment for Employee Development: Ivory Tower or Real World? Journal of Personality Assessment 100, 5 (2018), 507-517.

[26] Isabel Briggs Myers. 1962. The Myers-Briggs type indicator. Consulting Psychologists Press, Palo Alto, CA. (Original work published in 1943).

[27] Austin Lee Nichols and Jon K. Maner. 2008. The Good-Subject Effect: Investigating Participant Demand Characteristics. The Journal of General Psychology 135, 2 (2008), 151-166.

[28] Annie Murphy Paul. 2010. The Cult of Personality Testing: How Personality Tests Are Leading Us to Miseducate Our Children, Mismanage Our Companies, and Misunderstand Ourselves. Simon and Schuster, Simon \& Schuster Building, New York City.

[29] Charles J Pellerin. 2009. How NASA builds teams: Mission critical soft skills for scientists, engineers, and project teams. Wiley Online Library.

[30] Vreda Pieterse, Inge P. Sonnekus, and Derrick G. Kourie. 2006. Software Engineering Team Diversity and Performance. In Proceedings of the 2006 Annual Research Conference of the South African Institute of Computer Scientists and Information Technologists on IT Research in Developing Countries (SAICSIT '06). South African Institute for Computer Scientists and Information Technologists, Republic of
South Africa, 180-186. https://doi.org/10.1145/1216262.1216282

[31] Vreda Pieterse and Marko van Eekelen. 2016. Which Are Harder? Soft Skills or Hard Skills? In ICT Education: 45th Annual Conference of the Southern African Computer Lecturers' Association, SACLA 2016, Cullinan, South Africa, July 5-6, 2016, Revised Selected Papers. Communications in Computer and Information Science, Stefan Gruner (Ed.), Vol. 642. Springer International Publishing, Cham, 160 167.

[32] Richard Ryckman. 2007. Theories of Personality. Cengage Learning, Boston, MA.

[33] L. Silvestre, S. F. Ochoa, and M. Marques. 2015. Understanding the design of software development teams for academic scenarios. In 2015 34th International Conference of the Chilean Computer Science Society (SCCC). 1-6. https://doi.org/ 10.1109/SCCC.2015.7416570

[34] Randy Stein and Alexander B. Swan. 2019. Evaluating the validity of Myers-Briggs Type Indicator theory: A teaching tool and window into intuitive psychology. Social and Personality Psychology Compass 13, 2 (2019), e12434. https://doi.org/ 10.1111/spc3.12434

[35] Estelle Taylor. 2017. Student development and soft skills: IT-students at a university in South Africa. In Proceedings of the 10th International Conference of Information Systems (IADIS 2017), M. B. Nunes, P. Isaias, and P. Powell (Eds.). IADIS Press, http://www.iadisportal.org/contacts, 27-35.

[36] Bruce Thompson. 1996. Personal Preferences Self-Description Questionnaire. College Station, TX: Psychometrics Group (1996).

[37] Tammi Vacha-Haase and Bruce Thompson. 2002. Alternative Ways of Measuring Counselees' Jungian Psychological-Type Preferences. Fournal of Counseling \& Development 80, 2 (2002), 173-179.

[38] Tricia Varvel, Stephanie G. Adams, Shelby J. Pridie, and Bianey C. Ruiz Ulloa. 2004. Team Effectiveness and Individual Myers-Briggs Personality Dimensions. fournal of Management in Engineering 20, 4 (2004), 141-146.

[39] Simine Vazire. 2010. Who knows what about a person? The self-other knowledge asymmetry (SOKA) model. Fournal of personality and social psychology 98, 2 (2010), 281.

[40] M. Vijayalakshmi, P. D. Desai, and G. H. Joshi. 2012. An innovative approach to problem identification and design for capstone projects. In 2012 IEEE International Conference on Engineering Education: Innovative Practices and Future Trends (AICERA). Institute of Electrical and Electronics Engineers ( IEEE ), Piscataway, New Jersey, USA, 1 - 5. https://doi.org/10.1109/AICERA.2012.6306738

[41] Joseph B Wheelwright. 1964. Jungian Type Survey: The Gray-Wheelwright Test. San Francisco: Society of Jungian Analysts of Northern California (1964). 